\title{
PERANCANGAN APPLICATION PROGRAMMING INTERFACE (API) BERBASIS WEB MENGGUNAKAN GAYA ARSITEKTUR REPRESENTATIONAL STATE TRANSFER (REST) UNTUK PENGEMBANGAN SISTEM INFORMASI ADMINISTRASI PASIEN KLINIK PERAWATAN KULIT
}

\author{
${ }^{1}$ Beni Adi Pranata, ${ }^{2}$ Astria Hijriani dan ${ }^{3}$ Akmal Junaidi \\ 1,2,3 Jurusan Ilmu Komputer \\ Fakultas Matematika dan Ilmu Pengetahuan Alam \\ Universitas Lampung \\ Jl. S. Brodjonegoro No. 1, Bandar Lampung, 35145 \\ beniadipranata@gmail.com
}

\begin{abstract}
Application Programming Interface (API) is an interface built by system developer so some or entire functions of the system can programatically be accessed. Representational State Transfer (REST) is one of API development architectural style that uses Hypertext Transfer Protocol (HTTP) for data communication. This research implemented REST in developing API as the back-end of the skincare clinic patient information system. API was developed using Javascript Object Notation (JSON) as the standard format for data communication and JSON Web Token (JWT) as user authentication code. This research indicates that the development of API successfully performed on the patient administration of skin care clinic and implementation of REST makes it easy to develop API structures. This research produced REST API-based back-end for the patient administration information system of skin care clinic. API was tested in three stages: JWT testing on multiple backend servers, API testing with Equivalence Partitioning and system functional testing.
\end{abstract}

Keywords: application programming interface (api), hypertext transfer protocol (http), javascript object notation (json), json web token (jwt), representational state transfer (rest).

\section{Pendahuluan}

Dalam bidang ilmu kesehatan, pemanfaatan komputer untuk mendukung prosedur dan cara-cara dalam penyelenggaraan pelayanan kesehatan [12] dikenal dengan istilah komputerisasi administrasi [3]. Dukungan komputer pada administrasi pelayanan kesehatan yang difasilitasi oleh pihak konsultan teknologi informasi umumnya berbentuk sistem informasi. Dalam pengembangannya, konsultan teknologi informasi sebaiknya memperhitungkan bahwa kasuskasus yang dihadapi kliennya akan terus berkembang. Karena itu dibutuhkan sebuah konsep pengembangan yang baik supaya sebuah sistem informasi mampu beradaptasi. Memisahkan logic pada basis data dengan logic antarmuka dalam sebuah sistem informasi dianggap sebagai cara yang ideal untuk menanggulangi masalah ini. Dengan cara ini, masing-masing logic dapat dikembangkan secara terpisah dan dimungkinkan untuk mengakomodasi lebih banyak fungsi. Representasi fungsi-fungsi pada logic basis data yang diakses oleh logic pada antarmuka secara programmatis dikenal dengan istilah Application Programming Interface (API) [11]. 
Web merupakan sebuah ruang informasi yang digunakan secara global dan sumber informasinya diakses berdasarkan Hyper Text Transfer Protocol (HTTP) antara client dan server dengan konsep request-response [4]. Dalam pengembangan API diperlukan sebuah gaya arsitektur sebagai pedoman cara berhubungan antara logic basis data dengan logic antarmuka. Salah satu gaya arsitektur pengembangan API berbasis web yang menggunakan HTTP dalam komunikasi data adalah Representational State Transfer (REST) [1].

Penelitian ini mengimplementasikan gaya arsitektur REST dalam pengembangan API sebagai back-end sistem informasi administrasi pasien klinik perawatan kulit. API yang dikembangkan menggunakan Javascript Object Notation (JSON) [7] sebagai standar format dalam komunikasi data serta JSON Web Token (JWT) [5] sebagai kode otentikasi pengguna sistem. Penelitian ini menunjukkan bahwa pengembangan API berhasil dilakukan untuk administrasi pasien klinik perawatan kulit dan REST yang diterapkan mempermudah pengembangan struktur API. Penelitian ini menghasilkan back-end sistem informasi administrasi pasien klinik perawatan kulit berbasis REST API. API diuji dalam tiga tahap yakni pengujian otentikasi dengan JWT pada back-end server berjumlah banyak, pengujian API dengan metode Equivalence Partitioning dan pengujian fungsional sistem.

\section{Metodologi}

Pengembangan sistem pada penelitian ini dilaksanakan berdasarkan pendekatan-pendekatan baku yang mencakup cara-cara, teknik dan pemodelan dalam membangun sistem informasi. Hal ini dikenal dengan istilah System Development Life Cycle (SDLC) dan penelitian ini menggunakan SDLC tipe Waterfall. Tipe Waterfall digunakan karena dalam setiap tahapan penelitian mampu menerima perubahan dan pengembangan konsep dari tahapan sebelumnya, yang mana hal ini mendukung tujuan penelitian untuk membangun sistem yang mampu beradaptasi terhadap perkembangan proses bisnis diwaktu mendatang. Selain itu metode Waterfall juga telah terbukti berhasil dalam mengadaptasi penelitian dengan kasus serupa seperti "Sistem Perangkum Laporan Jaminan Pelayanan Kesehatan Medical Center PT. Central Pertiwi Bahari” [10] dan "TokenBased Authentication Using JSON Web Token on SIKASIR RESTful Web Service” [2].

Sebelum masuk ke tahap Waterfall, dilakukan studi literatur untuk mengumpulkan informasi penelitian-penelitian yang mengangkat topik pengembangan API dengan gaya arsitektur REST. Peneliti juga membangun komunikasi dan berdiskusi dengan administrator salah satu klinik kulit [8]. Kemudian pelaksanaan metode Waterfall dimulai dengan analisa kebutuhan sistem. Analisa kebutuhan dilakukan dengan mengembangkan literatur yang telah dikumpulkan berdasarkan proses bisnis administrasi pasien klinik kulit. Selanjutnya berdasarkan hasil analisa kebutuhan dilakukan desain server, desain database, desain kode program dan desain web server.

Tahap desain kemudian direalisasikan pada tahap implementasi. Tahap implementasi dimulai dengan membangun lingkungan pengembangan sistem. Selanjutnya mendesain struktur tabel, function dan stored procedure pada database. Dilanjutkan dengan mengembangkan back-end (coding) dan menyesuaikannya dengan database. Dan pada tahap akhir implementasi dibangun struktur rewrite pada web server untuk pemetaan akses API. Kemudian API diuji dengan bantuan 
software Postman [9] berdasarkan tiga skenario pengujian, antara lain : pengujian otentikasi token, pengujian dengan metode equivalent partitioning [6] dan pengujian fungsional.

\section{Pembahasan}

Hasil dari penelitian ini dibagi menjadi tiga bagian. Pertama adalah struktur API, kedua hasil REST API yang memetakan resource dan ketiga adalah pengujian untuk memastikan kesesuaian hasil penelitian.

\subsection{Struktur API}

Pada penelitian ini, resource diklasifikasi secara terpola berdasarkan path dan query string dalam URL serta request method dalam HTTP request. Klasifikasi resource berdasarkan path dan query string dibagi menjadi tiga pola sebagai berikut :

1. Titik akses /resource?query=string yang digunakan untuk request mendapatkan daftar dan menambah data anggota dari resource yang dimaksud.

2. Titik akses /resource/id?query=string yang digunakan untuk request mendapatkan detail, mengubah dan menghapus resource berdasarkan nomor id resource yang dimaksud.

3. Titik akses /parent/id/resource?query=string yang digunakan untuk request daftar dan menambah data anggota dari resource berdasarkan id parent yang dimaksud.

Sementara klasifikasi berdasarkan request method dibagi menjadi empat jenis sebagai berikut :

1. Request method POST yang digunakan untuk penambahan resource.

2. Request method GET yang digunakan untuk mendapatkan daftar dari anggota resource dan detail dari anggota resource.

3. Request method PUT yang digunakan untuk mengubah resource.

4. Request method DELETE yang digunakan untuk menghapus resource.

Kemudian klasifikasi diatas dipetakan terhadap resourcenya. Sebagian daftar API sebagai contoh yang menjelaskan hubungan antara resource dengan klasifikasinya terhadap path dan query string serta request method dapat dilihat pada Tabel 1.

Tabel 1 Contoh sebagian daftar API

\begin{tabular}{llcll}
\hline No & Nama Proses & $\begin{array}{l}\text { Request } \\
\text { Method }\end{array}$ & \multicolumn{1}{c}{ URI } & \multicolumn{1}{c}{ Keterangan } \\
\hline 1 & Post Registrasi & POST & /register & Mengirim email registrasi ke sistem \\
\hline 2 & Registrasi & POST & /user & Mengkonfirmasi email registrasi ke sistem \\
\hline 3 & Login & POST & /login & Membuat token untuk session \\
\hline 4 & Post Token & POST & /token & Membuat token permanen \\
\hline 5 & Post pasien & POST & /pasien & Menambah data pasien \\
\hline 6 & List pasien & GET & /pasien & Menampilkan daftar pasien \\
\hline 7 & Get pasien & GET & /pasien/<id_pasien> $>$ & $\begin{array}{l}\text { Menampilkan detail pasien berdasarkan ID } \\
\text { pasien }\end{array}$ \\
\hline
\end{tabular}




\begin{tabular}{ccccl}
\hline No & Nama Proses & $\begin{array}{l}\text { Request } \\
\text { Method }\end{array}$ & URI & Keterangan \\
\hline 8 & Update pasien & PUT & /pasien/<id_pasien> & $\begin{array}{l}\text { Mengubah detail pasien berdasarkan ID } \\
\text { pasien }\end{array}$ \\
\hline 9 & Delete pasien & DELETE & /pasien/<id_pasien> & Menghapus pasien berdasarkan ID pasien \\
\hline
\end{tabular}

Pada penelitian ini setiap request API yang masuk ke back-end server akan menghasilkan sebuah kembalian dengan format JSON. Kembalian tersebut akan dikelompokkan menjadi tiga bagian :

1. Head yang memuat informasi token.

2. Body yang memuat hasil dari eksekusi database.

3. Tail yang memuat pesan-pesan kesalahan.

Khusus untuk pengujian otentikasi tahap lanjutan, head juga akan memuat informasi back-end server yang memproses request.

\subsection{REST API}

Pada penelitian ini, REST API yang dihasilkan dipetakan kedalam bentuk tabel berdasarkan resource yang direpresentasikan. Untuk dapat memahami tabel REST API, berikut penjelasan dari setiap kolom dan tanda yang tersedia :

1. Kolom no sebagai nomor index dari parameter.

2. Kolom nama parameter sebagai nama dari parameter. Beberapa parameter yang tidak memiliki nomor index tidak dapat digunakan sebagai order. Selain itu terdapat empat parameter yang tidak akan memiliki index, parameter tersebut adalah offset, order, page dan sort. Keempat parameter ini merupakan parameter pembantu dalam operasi list, keterangannya sebagai berikut :

- offset merupakan parameter jumlah data yang ingin ditampilkan.

- order merupakan parameter order data berdasarkan nomor index parameter.

- page merupakan parameter halaman pada data yang ingin ditampilkan.

- $\quad$ sort merupakan parameter tipe pengurutan data dengan nilai 0 untuk ascending dan 1 untuk descending.

3. Kolom tipe data yang merupakan keterangan tipe data dari parameter beserta batasan maksimal dari nilai yang dapat ditetapkan pada parameter terkait.

4. Kolom parameter yang menginformasikan parameter yang wajib, dapat atau tidak boleh dikirimkan terhadap operasi tertentu. Informasi pada kolom ini diklasifikasikan sebagai berikut :

- (v) yang berarti parameter wajib dikirimkan.

- (x) yang berarti parameter tidak boleh dikirimkan.

- (-) yang berarti parameter dapat dikirimkan (opsional).

- $\quad$ (w) yang berarti parameter wajib dikirimkan melalui URI.

- (u) yang berarti patameter dapat dikirimkan (opsional) melalui URI.

5. Kolom nilai yang menentukan nilai minimal, maksimal dan nilai default yang dapat diterapkan pada parameter terkait.

Kemudian tiga contoh hasil REST API dari penelitian yang dihasilkan dari penelitian ini dapat dilihat pada tabel 2 hingga tabel 4 berikut : 
Tabel 2 User

\begin{tabular}{|c|c|c|c|c|c|c|c|c|c|}
\hline \multirow[b]{2}{*}{ No } & \multirow[b]{2}{*}{ Nama Parameter } & \multirow[b]{2}{*}{ Tipe Data } & \multicolumn{4}{|c|}{ parameter } & \multicolumn{3}{|c|}{ Nilai } \\
\hline & & & 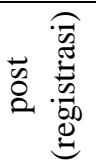 & $\begin{array}{l}\text { 崩 } \\
\text {. }\end{array}$ & 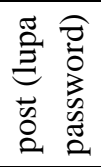 & 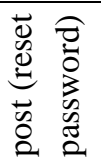 & $\stackrel{\Xi}{\Sigma}$ & 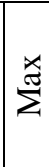 & 节 \\
\hline 1 & id & bigint(20) unsigned & $\mathrm{X}$ & $\mathrm{X}$ & $x$ & $\mathrm{x}$ & & & \\
\hline & email & varchar(50) & $\mathrm{v}$ & $\mathrm{V}$ & $\mathrm{V}$ & $\mathrm{V}$ & 5 & & \\
\hline & password & varchar(50) & $\mathrm{x}$ & $\mathrm{V}$ & $\mathrm{x}$ & $\mathrm{V}$ & 8 & & \\
\hline & token & varchar(256) & $\mathrm{x}$ & $\mathrm{V}$ & $\mathrm{x}$ & $\mathrm{V}$ & 1 & & \\
\hline
\end{tabular}

Tabel 3 Token

\begin{tabular}{|c|c|c|c|c|c|c|c|c|c|c|}
\hline \multirow{2}{*}{ No Nama Parameter } & \multirow{2}{*}{ Tipe Data } & \multicolumn{6}{|c|}{ parameter } & \multicolumn{3}{|c|}{ Nilai } \\
\hline & & . & 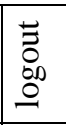 & $\begin{array}{l}\vec{n} \\
\text { ஜ }\end{array}$ & 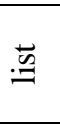 & 苟 & $\frac{\frac{\mathscr{U}}{0}}{\frac{0}{0}}$ & $\stackrel{\Xi}{\Sigma}$ & 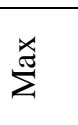 & 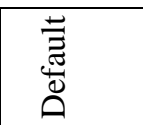 \\
\hline 1 id & bigint(20) unsigned & $\mathrm{x}$ & - & $\mathrm{x}$ & $\mathrm{x}$ & $\mathrm{V}$ & $\mathrm{V}$ & & & \\
\hline 2 user_id & bigint(20) unsigned & $\mathrm{x}$ & - & $\mathrm{x}$ & - & $\mathrm{x}$ & $\mathrm{x}$ & & & \\
\hline 3 created & timestamp & $\mathrm{x}$ & - & $\mathrm{x}$ & $\mathrm{x}$ & $\mathrm{x}$ & $\mathrm{x}$ & & & <current $>$ \\
\hline email & varchar(50) & $\mathrm{v}$ & - & $\mathrm{v}$ & $\mathrm{x}$ & $\mathrm{x}$ & $\mathrm{x}$ & 5 & & \\
\hline password & varchar(50) & $\mathrm{v}$ & - & $\mathrm{v}$ & $\mathrm{X}$ & $\mathrm{x}$ & $\mathrm{x}$ & 8 & & \\
\hline Ip & varchar(15) & $\mathrm{x}$ & - & - & $\mathrm{x}$ & $\mathrm{x}$ & $\mathrm{x}$ & 7 & 15 & $<$ current $>$ \\
\hline offset & tinyint(3) unsigned & $\mathrm{x}$ & $\mathrm{x}$ & $\mathrm{x}$ & - & $\mathrm{x}$ & $\mathrm{x}$ & 1 & 250 & 250 \\
\hline order & tinyint(2) unsigned & $\mathrm{x}$ & $\mathrm{x}$ & $\mathrm{x}$ & - & $\mathrm{x}$ & $\mathrm{x}$ & 0 & & 1 \\
\hline page & int(10) unsigned & $\mathrm{x}$ & $\mathrm{x}$ & $\mathrm{x}$ & - & $\mathrm{x}$ & $\mathrm{x}$ & 1 & & 1 \\
\hline sort & tinyint(1) unsigned & $\mathrm{x}$ & $\mathrm{X}$ & $\mathrm{x}$ & - & $\mathrm{x}$ & $\mathrm{x}$ & 0 & 1 & 0 \\
\hline
\end{tabular}


Tabel 4 Pasien

\begin{tabular}{|c|c|c|c|c|c|c|c|c|c|}
\hline \multirow{2}{*}{$\begin{array}{c}\text { Nama } \\
\text { Parameter }\end{array}$} & \multirow{2}{*}{ Tipe Data } & \multicolumn{5}{|c|}{ Parameter } & \multicolumn{3}{|c|}{ Nilai } \\
\hline & & $\begin{array}{l}\overrightarrow{\tilde{n}} \\
0 \\
0\end{array}$ & $\stackrel{\vec{n}}{\vec{a}}$ & טّ & \begin{tabular}{|l} 
\\
$\frac{\pi}{0}$ \\
0 \\
\end{tabular} & 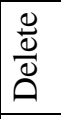 & $\stackrel{\Xi}{\Sigma}$ & 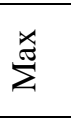 & 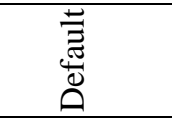 \\
\hline 1 Id & bigint(20) unsigned & $\mathrm{x}$ & $\mathrm{x}$ & $\mathrm{v}$ & $\mathrm{V}$ & $\mathrm{v}$ & & & \\
\hline 2 Nama & varchar(255) & $\mathrm{v}$ & $\mathrm{x}$ & $\mathrm{x}$ & - & $\mathrm{x}$ & 3 & & \\
\hline 3 Tempat & varchar(50) & V & $\mathrm{x}$ & $\mathrm{x}$ & - & $\mathrm{x}$ & 3 & & \\
\hline 4 Tanggal & date & - & $\mathrm{x}$ & $\mathrm{X}$ & - & $\mathrm{X}$ & & & \\
\hline 5 Alamat & varchar(255) & $\mathrm{V}$ & $\mathrm{x}$ & $\mathrm{X}$ & - & $\mathrm{X}$ & 3 & & \\
\hline 6 kecamatan & varchar(50) & - & $\mathrm{x}$ & $\mathrm{X}$ & - & $\mathrm{x}$ & & & \\
\hline 7 kabupaten & varchar(50) & - & $\mathrm{x}$ & $\mathrm{X}$ & - & $\mathrm{X}$ & & & \\
\hline 8 Provinsi & varchar(50) & - & $\mathrm{x}$ & $\mathrm{X}$ & - & $\mathrm{X}$ & & & "Lampung" \\
\hline $9 \mathrm{Jk}$ & tinyint(1) unsigned & - & $\mathrm{x}$ & $\mathrm{x}$ & - & $\mathrm{x}$ & 0 & 1 & 0 \\
\hline 10 Kawin & tinyint(1) unsigned & - & $\mathrm{x}$ & $\mathrm{X}$ & - & $\mathrm{x}$ & 0 & 1 & 0 \\
\hline 11 Berat & tinyint(3) unsigned & - & $\mathrm{x}$ & $\mathrm{X}$ & - & $\mathrm{x}$ & & & 50 \\
\hline Offset & tinyint(3) unsigned & $\mathrm{X}$ & - & $\mathrm{x}$ & $\mathrm{X}$ & $\mathrm{x}$ & 1 & 250 & 250 \\
\hline Order & tinyint(2) unsigned & $\mathrm{X}$ & - & $\mathrm{X}$ & $\mathrm{X}$ & $\mathrm{x}$ & 0 & & 1 \\
\hline Page & int(10) unsigned & $\mathrm{X}$ & - & $\mathrm{X}$ & $\mathrm{X}$ & $\mathrm{X}$ & 1 & & 1 \\
\hline Sort & tinyint(1) unsigned & $\mathrm{X}$ & - & $\mathrm{X}$ & $\mathrm{x}$ & $\mathrm{x}$ & 0 & 1 & 0 \\
\hline
\end{tabular}

\subsection{Pengujian}

Pengujian sistem dalam penelitian ini dibagi menjadi tiga tahap, yakni pengujian otentikasi, pengujian nilai masukan dengan equivalence partitioning dan pengujian fungsional sistem.

\subsubsection{Pengujian Otentikasi}

Pengujian otentikasi dimulai dengan membangun sebuah lingkungan pengujian berupa loadbalanced server bertipe round-robin menggunakan Nginx dengan tiga back-end server seperti yang terlihat pada Gambar 1. 


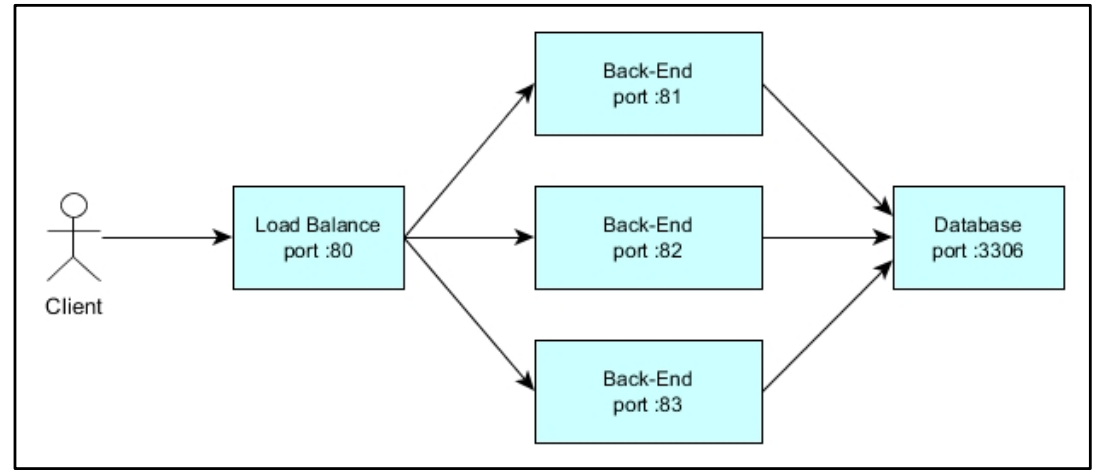

Gambar 1 Skema load-balanced server

Pengujian otentikasi dilakukan sebanyak tiga kali dengan melakukan request login pada salah satu back-end server, kemudian dilanjutkan dengan mengirim HTTP request kepada back-end server yang berbeda. Hal ini dilakukan untuk memastikan JWT mampu memenuhi tanggung jawab menggantikan sistem session konvensional sehingga otorisasi pengguna dapat dimengerti oleh back-end server yang berbeda meskipun otentikasi hanya dilakukan pada salah satu backend server saja. Request yang dikirim kepada back-end server merupakan sampel request untuk mendapatkan list pasien saja. Untuk membantu identifikasi back-end server yang memproses request, khusus untuk pengujian ini telah ditambahkan informasi port server di bagian head pada nilai kembalian.

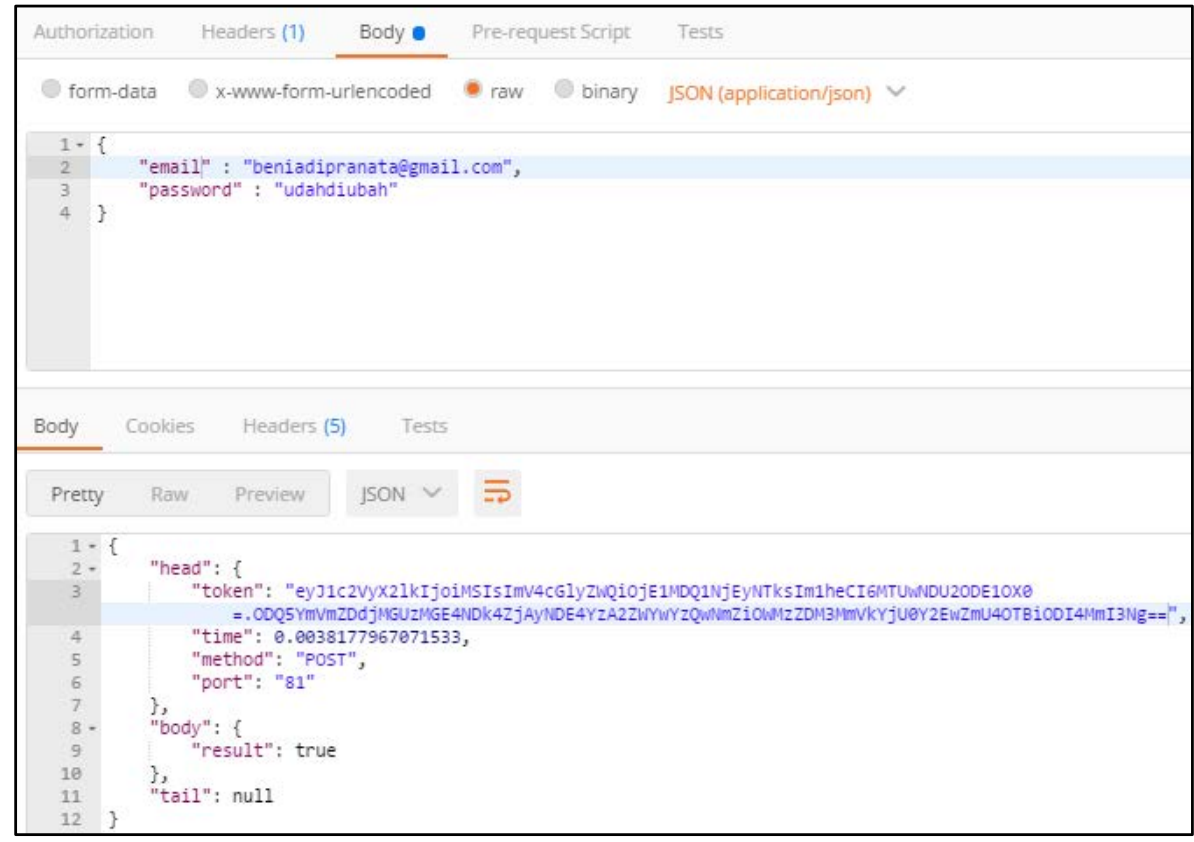

Gambar 2 Pengujian otentikasi diproses oleh back-end server pertama 
Pada gambar 2 dapat dilihat bahwa otentikasi pengguna diproses pada back-end server pertama (port 81) dan telah menghasilkan token. Token yang dihasilkan selanjutnya akan digunakan sebagai token otorisasi pada back-end server yang lain.

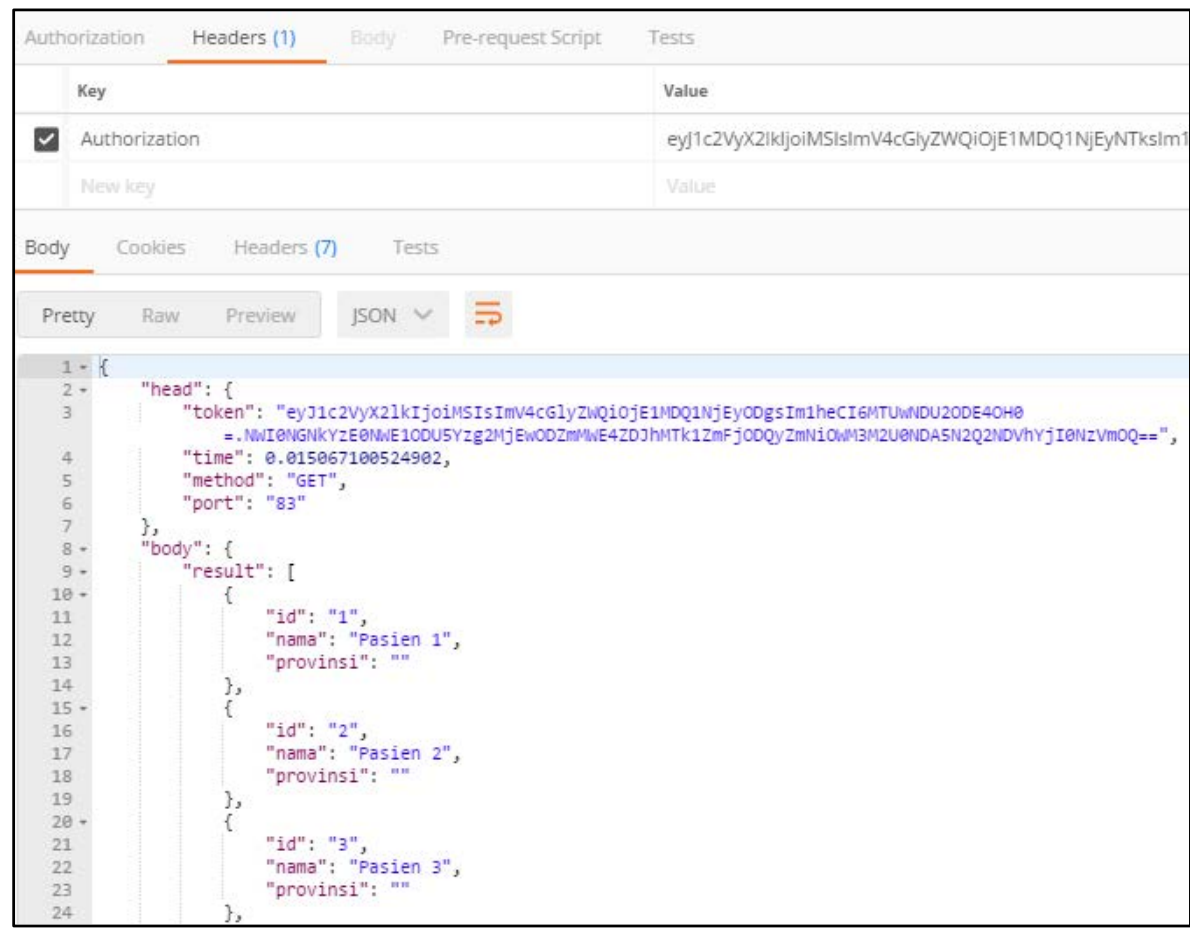

Gambar 3 Pengujian otentikasi diproses oleh back-end server kedua

Pada gambar 3 dapat dilihat bahwa token yang sebelumnya dihasilkan pada back-end server pertama telah dimengerti oleh back-end server ketiga (port 83). Dan pada hasil kembalian diperoleh sebuah token baru pada bagian head serta daftar pasien pada bagian body.

\subsubsection{Pengujian Equivalence Partitioning}

Telah dilakukan pengujian dengan metode equivalence partitioning [5] seperti yang telah direncanakan pada metodologi. Contoh sebagian hasil pengujian dapat dilihat pada Tabel 5.

Tabel 5 Contoh sebagian hasil pengujian equivalence partitioning

\begin{tabular}{|c|c|c|c|c|}
\hline Kode Uji & $\begin{array}{c}\text { Daftar } \\
\text { Pengujian }\end{array}$ & Kasus Uji & Hasil yang Diharapkan & Hasil \\
\hline & $\begin{array}{l}\text { Validasi } \\
\text { path }\end{array}$ & Request method GET untuk /pasien & $\begin{array}{l}\text { Sukses mendapatkan list } \\
\text { pasien }\end{array}$ & Berhasil \\
\hline
\end{tabular}




\begin{tabular}{|c|c|c|c|c|}
\hline Kode Uji & $\begin{array}{c}\text { Daftar } \\
\text { Pengujian }\end{array}$ & Kasus Uji & Hasil yang Diharapkan & Hasil \\
\hline \multirow{9}{*}{$\begin{array}{l}\text { Path dan } \\
\text { request } \\
\text { method }\end{array}$} & & $\begin{array}{l}\text { Request method GET untuk } \\
\text { /pasien/1 }\end{array}$ & $\begin{array}{l}\text { Sukses mendapatkan detail } \\
\text { pasien Id } 1\end{array}$ & Berhasil \\
\hline & & $\begin{array}{l}\text { Request method GET untuk } \\
\text { /pasien/1/invoice }\end{array}$ & $\begin{array}{l}\text { Sukses mendapatkan list } \\
\text { invoice untuk pasien Id } 1\end{array}$ & Berhasil \\
\hline & & $\begin{array}{l}\text { Request method GET untuk } \\
\text { /pasien/1/invoice/1 }\end{array}$ & $\begin{array}{l}\text { Error dengan kode } 404 \text { - not } \\
\text { found }\end{array}$ & Berhasil \\
\hline & & Request method GET untuk /salah & $\begin{array}{l}\text { Error dengan kode } 404 \text { - not } \\
\text { found }\end{array}$ & Berhasil \\
\hline & \multirow{5}{*}{$\begin{array}{l}\text { Validasi } \\
\text { request } \\
\text { method }\end{array}$} & $\begin{array}{l}\text { Request method POST untuk } \\
\text { /pasien }\end{array}$ & $\begin{array}{l}\text { Sukses menginput record } \\
\text { pasien baru }\end{array}$ & Berhasil \\
\hline & & Request method GET untuk /pasien & $\begin{array}{l}\text { Sukses mendapatkan list } \\
\text { pasien }\end{array}$ & Berhasil \\
\hline & & $\begin{array}{l}\text { Request method GET untuk } \\
\text { /pasien/1 }\end{array}$ & $\begin{array}{l}\text { Sukses mendapatkan detail } \\
\text { pasien Id } 1\end{array}$ & Berhasil \\
\hline & & $\begin{array}{l}\text { Request method PUT untuk } \\
\text { /pasien/1 }\end{array}$ & $\begin{array}{l}\text { Sukses mengedit data pasien } \\
\text { dengan Id } 1\end{array}$ & Berhasil \\
\hline & & $\begin{array}{l}\text { Request method DELETE untuk } \\
\text { /pasien/1 }\end{array}$ & $\begin{array}{l}\text { Sukses menghapus data } \\
\text { pasien dengan Id } 1\end{array}$ & Berhasil \\
\hline
\end{tabular}

\subsubsection{Pengujian Fungsional Sistem}

Pengujian fungsional sistem REST API dilakukan secara keseluruhan. Pengujian diklasifikasikan menjadi tiga bagian utama yakni pendaftaran pengguna, proses pembuatan token (pada proses login dan pembuatan token permanen) dan pengaksesan API. Contoh beberapa hasil pengujian dapat dilihat pada Tabel 6 .

Tabel 6 Contoh sebagian hasil pengujian fungsional

\begin{tabular}{lllc}
\hline No & \multicolumn{1}{c}{ Nama Proses } & Keterangan & Hasil \\
& & Pengujian \\
\hline 1 & Post Registrasi & Mengirim email registrasi ke sistem & Berhasil \\
\hline 2 & Registrasi & Mengkonfirmasi email registrasi ke sistem & Berhasil \\
\hline 3 & Login & Membuat token untuk session & Berhasil \\
\hline 4 & Post Token & Membuat token permanen & Berhasil \\
\hline 5 & Post pasien & Menambah data pasien & Berhasil \\
\hline 6 & List pasien & Menampilkan daftar pasien & Berhasil \\
\hline 7 & Get pasien & Menampilkan detail pasien berdasarkan ID pasien & Berhasil \\
\hline 8 & Update pasien & Mengubah detail pasien berdasarkan ID pasien & Berhasil \\
\hline 9 & Delete pasien & Menghapus pasien berdasarkan ID pasien & \\
\hline
\end{tabular}




\section{Kesimpulan}

Dalam penelitian ini gaya arsitektur REST berhasil diimplementasikan pada sistem administrasi pasien klinik perawatan kulit. Gaya arsitektur REST pada API menggunakan path, query dan request method dalam mengklasifikasi resource. Kemudian pengujian otentikasi REST API dalam penelitian ini memperoleh keberhasilan penuh karena JWT telah dimengerti oleh semua back-end server. Begitu pula untuk pengujian masukan sistem dengan metode equivalence partitioning dan pengujian fungsional sistem.

Hasil dari penelitian ini butuh pengembangan lebih lanjut sebelum dapat digunakan oleh awam, khususnya untuk pengembangan sistem antarmuka. Sebagai saran dari peneliti, dalam pengembangan REST API yang cara akses resourcenya memiliki banyak kesamaan pola, akan lebih baik jika kode program dibuat berstruktur dengan class dan fungsi.

\section{Refference}

[1] Fielding, Roy Thomas. 2000. Architectural Styles and the Design of Network-based Software Architectures. University of California, Irvine.

[2] Haekal, Muhamad dan Eliyani. 2016. Token-based authentication using JSON Web Token on SIKASIR RESTful Web Service. International Conference on Informatics and Computing (ICIC).

[3] Haryadi, Hendi. 2009. Administrasi Perkantoran untuk Manajer dan Staf. Jakarta: Transmedia Pustaka.

[4] Hidayatullah, Priyanto dan Jauhari Khairul Kawistara. 2015. Pemrograman Web. Bandung: Informatika Bandung.

[5] Jones, Michael B. dkk. 2015. JSON Web Token (JWT). Internet Engineering Task Force (IETF), Mei 2015.

[6] Jovanoic, Irena. 2009. Software Testing Methods and Techniques. The IPSI BgD Transactions on Internet Research.

[7] Kleppmann, Martin dan Alastair R. Beresford. 2017. A Conflict-Free Replicated JSON Datatype. University of Cambridge Computer Laboratory, Cambridge.

[8] Riani, Istiasih Fajar. 2017. Wawancara Administrasi Pelayanan Kesehatan. Lampung.

[9] Postdot Technology. 2017. Postman is the most complete API Development Environment. [Online]. San Francisco. Tersedia: https://www.getpostman.com/postman [13 September 2017].

[10] Pranata, Beni Adi. 2014. Sistem Perangkum Laporan Jaminan Pelayanan Kesehatan Medical Center PT. Central Pertiwi Bahari. Lampung.

[11] Rama, Girish Maskeri dan Avinash Kak. 2013. Software - Practice and Experience. New Jersey: Wiley Online Library.

[12] Republik Indonesia. 2009. Undang-Undang No. 36 Tahun 2009 tentang Kesehatan. Jakarta: Sekretariat Negara. 